\title{
Notes on the vocalizations of Chestnut-bellied Monarch (Monarcha castaneiventris)
}

Peter Boesman

In the following we briefly analyze and compare voice of the four races of Chestnut-bellied Monarch (Monarcha castaneiventris). We also try to quantify the extent of any vocal differences using the criteria proposed by Tobias et al. (2010), as a support for taxonomic review. We have made use of sound recordings available on-line from Xeno Canto (XC) and Macaulay Library (ML).

HBW (Clement 2016) writes for song a rapid series of whistles "kwee kwee kwee kwee kwee", but this seems to be in error. From the available recordings, song seems to be rather a long whistle repeated at intervals:

\section{$\underline{\text { Race castaneiventris }}$}

Presumed song is a repeated fluting whistle at about even pitch or slightly descending

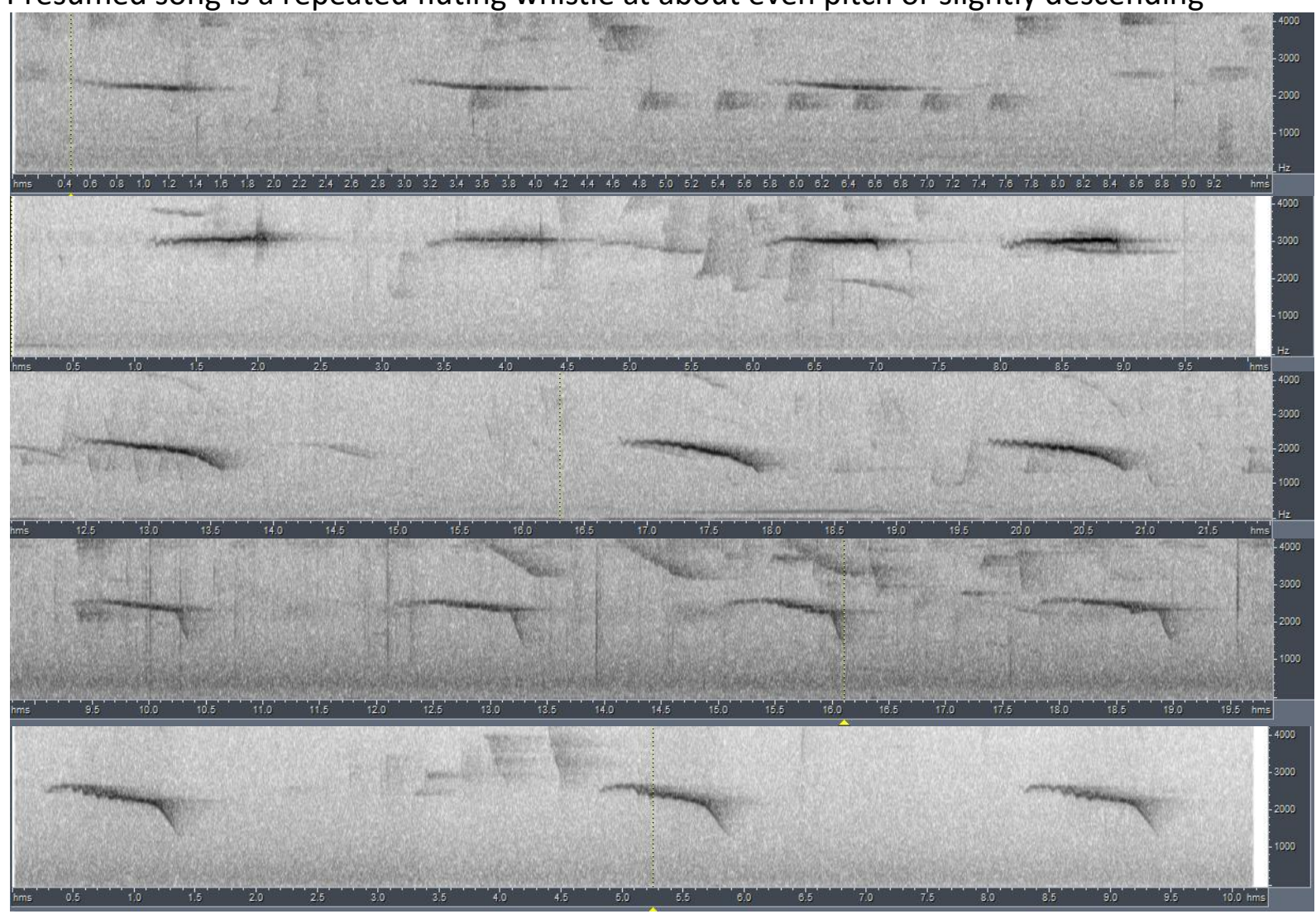

Race obsciurior: no available recordings 

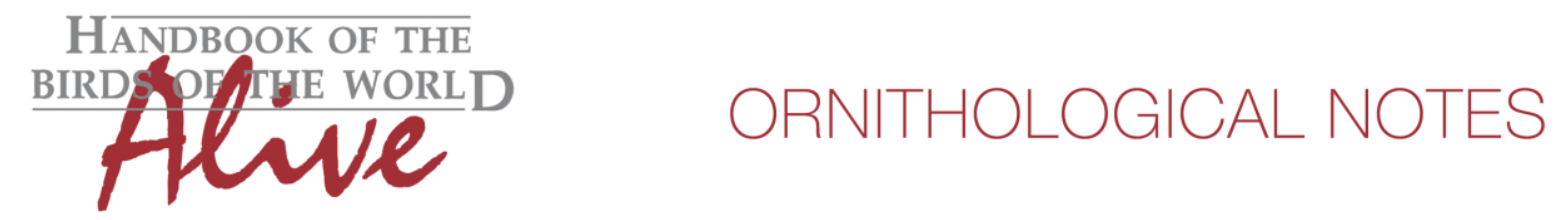

\section{Race megarhynchus}

Presumed song is a repeated fluting whistle, which has a rising and falling part, usually one of both emphasized and having the largest frequency range

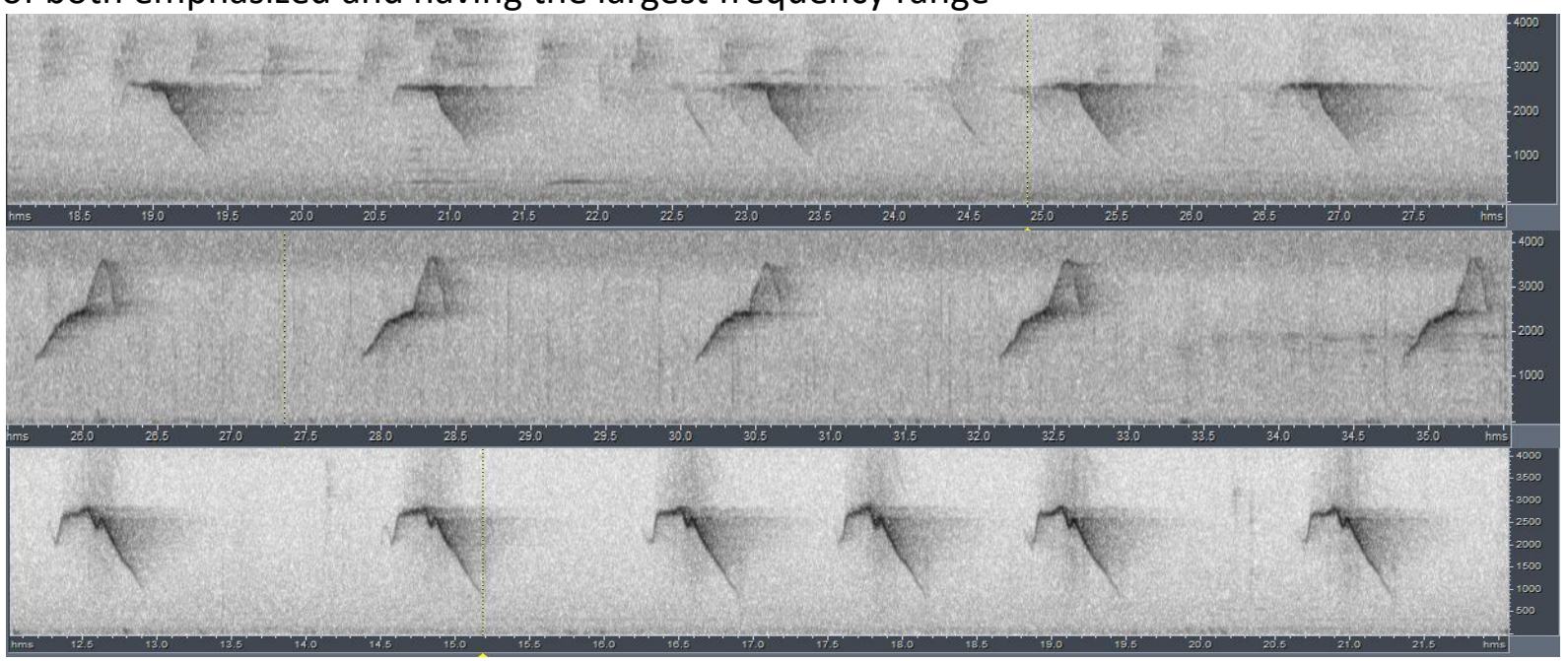

Race ugiensis $(\mathrm{n}=1)$

Presumed song consists of 3 whistles, the middle one being by far the longest "du-wheee-it"

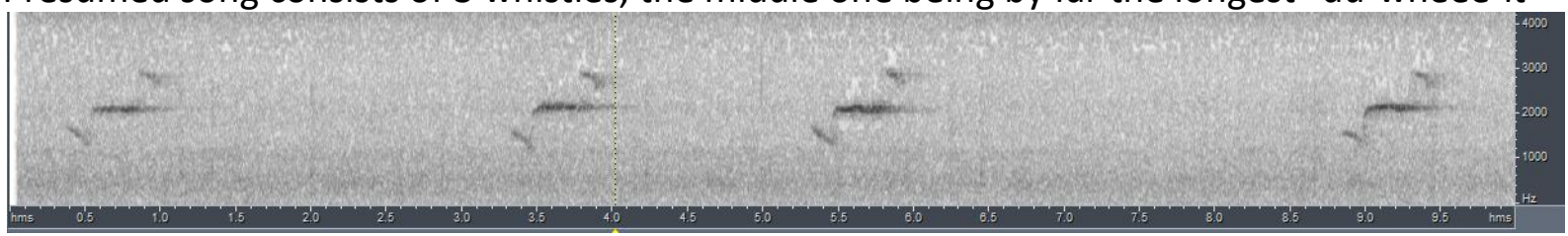

From the above, it would appear that the 3 taxa all have a diagnostic song, ugiensis being the most pronounced having a phrase of 3 notes rather than a single whistle.

Vocal differences can thus be quantified as follows:

ugiensis vs other races: 3-note phrase vs single whistle (score 3) (or alternatively a clearly shorter whistle-length (score 3 )) and seemingly different call (score 1). When applying Tobias criteria this would lead to a total vocal score of 4.

castaneiventris vs megarhynchus: latter has larger frequency range (c. $1500-2200 \mathrm{~Hz}$ vs $200-$ $1200 \mathrm{~Hz}$, score 2-3), shorter note length (c. $0.7-0.9 \mathrm{~s}$ vs $1.0-1.4 \mathrm{~s}$, score 2-3) and different note shape (score 1 ), leading to a total vocal score of at least 4.

A note of caution: XC33019 from N San Cristobal (where megarhynchus is supposed to occur) has whistles very similar to castaneiventris, and even more surprising, has as a note 'all glossy black' and designated race is ugiensis. This may indicate both that there is also (rarely) a black phase on the larger islands (or true ugiensis ??) AND that castaneiventris and megarhynchus(or uguensis??) occasionally have the same song. This will have to be investigated further. 

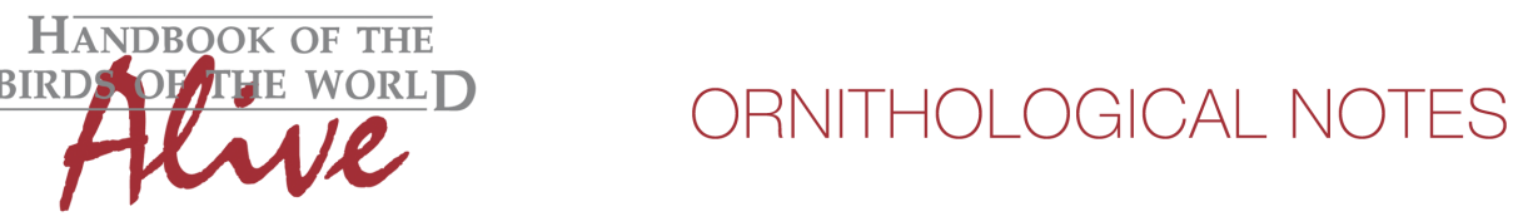

This note was finalized on 22nd January 2016, using sound recordings available on-line at that moment. We would like to thank in particular the sound recordists who placed their recordings for this species on XC and ML: Eleanor Brown, David Gibbs, Phil Gregory, Niels Krabbe, Frank Lambert and Mark Robbins.

\section{References}

Clement, P. (2016). Chestnut-bellied Monarch (Monarcha castaneiventris). In: del Hoyo, J., Elliott, A., Sargatal, J., Christie, D.A. \& de Juana, E. (eds.). Handbook of the Birds of the World Alive. Lynx Edicions, Barcelona. (retrieved from http://www.hbw.com/node/59224 on 22 January 2016).

Tobias, J.A., Seddon, N., Spottiswoode, C.N., Pilgrim, J.D., Fishpool, L.D.C. \& Collar, N.J. (2010). Quantitative criteria for species delimitation. Ibis 152(4): 724-746.

\section{Recommended citation}

Boesman, P. (2016). Notes on the vocalizations of Chestnut-bellied Monarch (Monarcha castaneiventris). HBW Alive Ornithological Note 195. In: Handbook of the Birds of the World Alive. Lynx Edicions, Barcelona. (retrieved from http://www.hbw.com/node/932140 on 29 August 2016). 